\title{
COLONIAL MOBILITY AND THE BIOPOLITICS OF THE COLONIAL NON-PLACE*
}

\author{
Jinhyoung Lee \\ Konkuk University \\ gespenst@konkuk.ac.kr
}

\begin{abstract}
By approaching Namcheon Kim's short story "On the Road" (1939) from the new mobilities paradigm, this paper explores the paradoxical relationship between the colonial government and the postcolonial politics in late colonial Korea. In this short story, the Korean territories in the late 1930 s are represented as colonial "non-places," in which is exercised imperialistic biopower through colonial mobility. The Korean people residing in the non-places are characterized as bare lives on-the-move who only seek to survive, yielding their political rights to the imperialistic biopower. Thereby, this short story demonstrates the reorganization of the colonial territory as a colonial non-place and the transformation of the Korean population into colonial subjects in order to stabilize the Japanese colonial regime. However, considering that the bare lives on-the-move are divested of any identity, relations, and history, the colonial nonplace might be construed to be disclosing the vulnerability of the Japanese colonial regime and, thus, the possibility of postcolonial politics.
\end{abstract}

\section{Keywords}

Bare Life; Colonial Mobility; Colonial Non-Place; Humanitarianism; Imperialistic Biopower; Postcolonial Politics

* This work was supported by the Ministry of Education of the Republic of Korea and the National Research Foundation of Korea (NRF-2018S1A6A3Ao3043497) 


\begin{abstract}
About the Author
Jinhyoung Lee is Assistant Professor at the Academy of Mobility Humanities, Konkuk University, South Korea. He earned his PhD from Yonsei University and completed a post-doctoral fellowship at Seoul National University. In addition to his book Theories of Novel of the Colonial Korea in the Late 1930's (2013), he has co-authored other books including Text, Technology and Mobility (2019), After Hybridity (2017), Criticism of Korean Multiculturalism (2016), and the like. He also translated Haim Hazan's Against Hybridity (2020) and co-translated Linda Hutcheon's A Theory of Adaptation (2017) into Korean, as well as Mikhail Bakhtin: Creation of a Prosaics (2006) by Gary Saul Morson and Caryl Emerson. His interests include the modern Korean novel and criticism in the colonial era, diaspora, hybridity, (post)coloniality, and mobility humanities studies.
\end{abstract}




\section{NEW MOBILITIES PARADIGM AND NON-PLACES}

This paper explores the paradoxical relationship between the colonial government and postcolonial politics in late colonial Korea by analyzing Namcheon Kim's short story "On the Road" (1939) from the new mobilities paradigm. In this exploration, it reconsiders Marc Augé's concept of "non-places" via Sarah Sharma's arguments and examines colonial mobility and the colonial non-place. Thereby, the story reveals the colonized population as bare lives on-the-move and discloses the vulnerability of the Japanese colonial regime.

In general, the new mobilities paradigm refers to a theory that views the social world in terms of broad economic, social, and political practices, infrastructures, and ideologies which govern the movement of people, thoughts, information, and things (Urry 18). Being emphasized in this paradigm are "complex mobilities of all kinds as the basis of all forms of space," which looks into "how these political economic relational spaces were produced in and through social and cultural practices" (Sheller 3, emphasis supplied). In other words, the paradigm views a relational space to be constitutive of "movement, potential movement and blocked movement" (Urry 43), and regards different forms of movements as being governed by mobility-related economic, social, and political practices, infrastructures, and ideologies-in short, "mobilities."

From this paradigm, this paper examines colonial Korea as the colonized space in which Japanese imperialism had tried to control the Korean population mainly by developing mobility technologies and infrastructures. In this regard, Augé's concept of non-places is instructive, which was initially understood to characterize what he called "supermodernity," which refers to the transient spaces formed in relation to certain ends as well as the superficial relations between individuals and these spaces (94). However, as he points out, non-spaces are not absent from modernity (92), and the notion of non-spaces cannot only be applied to a particular time in history, the postmodern, but also to transient spaces composed of such superficial relations in another time. ${ }^{1}$

It is notable that, for Augé, the non-place denotes a non-anthropological place as a result of the loss of people's sense of belonging to a place, which is coupled with increasing movement due to advancements in mobility infrastructures. Contrary to the notion of anthropological place where people can obtain a sense of individual identity resulting from their belonging to a place, the non-place gives them only "relative anonymity" (101). Its archetype is a traveler's space whereby "neither identity, nor relations, nor history really makes any sense" (87). The nonplace can thus be rendered as "the 'duty-free' space" (101), which provides people not just a sense of solitude but also a sense of comfort by allowing them to be 
anonymous. It is "the unrooted place marked by mobility and travel," which does not permit people to be "existential insiders" in it (Cresswell 44-46).

Augé's arguments of non-place can be reevaluated from the new mobilities paradigm. Theycan be considered as not merely a description of non-anthropological space, but also as an "anthropological" explanation for the relational spaces consisting of movement, potential movement, and blocked movement, which are constructed through mobilities. In this regard, Sarah Sharma argues that the nonplace must be acknowledged as "housing a very specific politics of place wherein the logic of the camp and the spectacle collide" (130). She contends that, in the non-places such as international airports or shopping malls, the logic of exclusion or "the state of exception," which exists in a refugee camp, is contemporaneous with the logic of the spectacle that reigns in the space of commodification or consumption (130-131). This is to say that the two spaces of spectacle and exception are common in their deprivation of identity, relations, and history, namely, their anonymity; and in these spaces, people are bare lives, forced to be divested of their humanity politically or economically.

Reconsidered from Sharma's discussion of "a mixed regime of camp and spectacle," ${ }^{2}$ the non-place would further clarify the paradoxical relationship between the colonial government and the postcolonial politics, toward conceptualizing colonial mobility and colonial non-place. Prior to its occupation of Korea (19101945), Japanese imperialism enthusiastically participated in constructing mobility infrastructures in the Korean Peninsula, including Gyeongin Railroad Line [SeoulIncheon], its first railway, in 1899, and Gyeongbu Railroad Line [Seoul-Busan], which would later link Manchuria and Japan in 1904. After its occupation of Korea, it aggressively propelled the development of colonial mobility across the colonized country, which comprised of railways, roads, and seaways. These civil engineering works were undoubtedly designed for manifest imperialistic purposes, including Japan's mobilization of people, resources, and agricultural products and its territorial expansion to Manchuria, China. More importantly, they were conducted to perpetuate the Japanese domination of Korea (Cho 8-25), wholly reorganizing the colonized territory and disciplining the colonized population's daily movements to adapt to the transformed milieu.

The colonial mobility that the Japanese Government-General of Korea, the Japanese colonial government organization in the Korean Peninsula from 1910 to 1945, had developed allowed the Korean Peninsula to display not only a space of spectacle, replete with colonial mobilities - including train, bus, railway, roadway, bus stop, and the like-but also the camp with which the imperialistic biopower governed the colonized by disciplining their movements through colonial mobility. For example, the construction of mobility infrastructures in colonial Korea, which 
the colonial government had implemented in the 1930s, was also publicized as aiming at helping the needy and the unemployed in colonial Korea. In addition to the imperialistic reorganization of the colonized territory, such mobilization of the Koreans to the construction site compelled them to uproot their taken-forgranted identity, relations, and history for survival. Their uprootedness rendered them anonymous, divested of political rights in the colonized territory; that is, the colonial non-place. Thus, the colonial non-place can fundamentally be rendered as the space of imperialistic biopolitics in which the colonized population are deemed as anonymous beings on-the-move-the bare lives lacking identity, relations, and history. Thereby, the colonial non-place in which living beings have no rights can paradoxically also bring about the failure of Japanese imperialism.

Drawing from the theoretical reflections above, this paper delves into the paradoxical relationship between the colonial government and postcolonial politics in late colonial Korea in the analysis of Namcheon Kim's short story "On the Road" (1939). Its story is simple: On the road halfway to his trip back to Seoul, Yeongchan Park meets $\mathrm{K}$, a civil engineer and a younger brother of his former comrade, by chance. He stays overnight at K's abode, a temporary residence near the railway construction site, conversing with him, playing with terrapins in a box, and drinking together. The following day, Park tries but finally fails to carry to his house three terrapins, which are mementos from $\mathrm{K}$, since the glass bottle containing them got broken in the bus on the way to Seoul.

What is immediately striking in Kim's short story is its spatial setting. Such transient spaces-namely, the road, the bus stop, and the interior of the bus-in which its main events occur might be readily considered as non-places. It is more noteworthy that they were situated at a specific temporal node: a point in time nearing the completion of the "12 Years Plan of Korean Railroad" (1927-1938). This temporal node gave rise to the dramatic expansion of the network of Korean interregional railways, as well as the beginning of the construction of Jungang Railroad Line (1936-1941), which was designed to cover 12 percent of the Korean territory (Jeong 147-158). Also, it is the point in time when preparations were underway by the Japanese Government-General of Korea for holding the 3oth Anniversary Exhibition of Colonial Administration (1940). It was the biggest in colonial Korea. The anniversary exhibition was meant to extensively publicize the 30 years of Japanese colonialism at a planned site of the railway station in Seoul, which was the starting point of Jungang Railroad Line. In this respect, Kim's work may be said to problematize the colonized space of the time in which the colonial government self-publicized its success, proud and convinced that colonial mobility had been virtually completed, resulting in the stabilization of the colonial regime. 
In Kim's work, figures are portrayed as beings on-the-move: family members waiting for the bus going to the construction site, a civil engineer and railway workers residing in their temporary residence, and the narrator, Yeongchan Park, traveling from Chuncheon to Seoul. It is notable that except for the narrator and the civil engineer, an actor of the colonial government, the other Koreans are portrayed as living beings, one of whom has a Korean name as a token of his nationality, but most of whom remain anonymous. They are the colonized people who are unceasingly moving, going somewhere to make a living - regardless of their identity, relations, and history-thereby resulting in a superficial connection to transient places: the colonial non-places. Also, by strongly associating them with the terrapins, Kim's work fundamentally characterizes them as living bare lives, seeking nothing more than mere survival. However, their anonymity seems to disclose the imperialistic biopolitics' vulnerability, making room for postcolonial politics by demonstrating their impotence as social or political subjects.

The next section outlines Kim's short story's historical context, which is indispensable in addressing the story's specificity in terms of time and space, namely, colonial Korea in the late 1930s. In the following discussion, the events occurring in transient places-on the road, at the bus stop, and the interior of the bus-are to be analyzed, which would help unravel the paradoxical relationship between the colonial government and postcolonial politics, as well as the impossible maintenance of the Japanese colonial regime.

\section{COLONIAL MOBILITY AND EMERGENCE OF COLONIAL NON-PLACE}

Modern mobility infrastructures in the Korean Peninsula were predominantly developed by Japanese imperialism, as it aspired to expand its territory to Manchuria, China. Following its construction of the Gyeongin Railroad Line [Seoul-Incheon] in 1899 and Gyeongbu Railroad Line [Seoul-Busan] in 1904, Japanese imperialism completed the building of the cardinal traffic network linking Japan and Manchuria in 1911, the year after the Japanese occupation of Korea. It inaugurated a cross-channel liner between Busan, Korea, and Shimonoseki, Japan, in 1905 and, subsequently, a bridge connecting Sinuiju, Korea, to Andong, Manchuria, in 1911 (Cho 9). It also launched the construction of modern roads across the Korean Peninsula, seizing local administrative authority in Korea through the constitution of the Japanese Resident-General of Korea in 1906. ${ }^{3}$ The move was based on "An Investigation Report on Korean Public Works" (1905) that a Japanese research group on Korean roads submitted to Japanese Ministry of Interior as the outcome of its detailed reconnaissance survey (Huh and Todoroki 173-176). 
Just after its occupation of Korea in 1910, Japanese imperialism enthusiastically set colonial mobility in motion; for example, it allocated 20 percent of the total budget of the Japanese Government-General of Korea in the 1910s to erect railways, roads, and ports nationwide (Ko 275-280). In 1910, it initiated the construction of its railroad network, linking the four corners of the peninsula as a central axis of the colonial mobility system by launching the construction of the Honam Railroad Line [Daejeon-Mokpo] that covered the southwestern area of colonial Korea and Gyeongwon Railroad Line [Seoul-Wonsan] that covered the northeastern area of colonial Korea. Also, by establishing and carrying out the "12 Years Plan of Korean Railroad" (1927-1938) and, consecutively, "the Plan of Construction of Jungang Railroad Line in Korea" (1936-1941), it had reinforced and enlarged dramatically the colonial railroad network to encompass the whole colonized territory. Notably, although promoting the local travels of people in colonial Korea, this railroad network was fundamentally intended to facilitate the transportations of people, resources, and agricultural products between Japan, Korea, and Manchuria mainly for economic and military purposes (Jeong 139-166).

As the majority of newly inaugurated seaways and ports were connected to the railroad network for the Japanese international transportation, automobile traffic was also intended to underpin the railroad network by linking small villages to the railway stations while also facilitating the interlocal travels of the population and products in the interior of the peninsula. In this regard, it is notable that most of the new roads constructed by Japanese imperialism were not according to the old paths, which people had used in the last several hundred years. Contrary to the traditional land transportation system, which in the Joseon Dynasty (1392-1910) was formed radially centered on Seoul and local administration canters, Japanese imperialism built roads typically following the colonial traffic system, linking the new roads to railway stations, open ports, and local economic hubs (Huh and Todoroki 176-177), ignoring thus the traditional routes. In short, the development of the colonial mobility system was contemporaneous with the process of marginalizing traditional mobility, simultaneously reorganizing the colonized territory.

By enacting a series of rules and acts regarding the public works, the Japanese Government-General of Korea continued to establish colonial mobility and to reconfigure the colonized territory, aiming to stabilize and perpetuate the Japanese colonial regime in the peninsula. For example, the colonial government designed roads in colonial Korea by taxonomizing them according to four grades based on their administrative and military effectiveness, not on the Korean population's needs, through the enactment of the "Rules of the Road" (1911). By promulgating the "Ordinance of the Expropriation of Land" in 1911, it laid the legal groundwork to forcibly expropriate the Koreans' lands for establishing mobility infrastructures without any compensation (Cho 18). In addition, it sought to control the logistics 
and movements of the population in the peninsula by promulgating the "Ordinance of the Korean Automobile Traffic" (1934), which invested its Railway Bureau with full powers to manage private and public automobile traffic (Cho et al. 265-274). Also, by issuing the "Ordinance of the Korean Road" (1938), its power of controlling mobilities in the peninsula was considerably intensified. Hence, the nationwide erection of colonial mobility fundamentally spread out the colonial government's administrative power into every corner of the peninsula resulting in the concrete Japanization of the Korean territory.

On the other hand, the improvement of mobility infrastructures in colonial Korea facilitated the movement of the population interregionally or across the border. Specifically, during the Great Depression in 1929, the Korean farm workers, including independent farmers and peasants who consisted of $80 \%$ of the total Korean population at this time (Lee and Cheon 409), suffered immeasurably from terrible economic hardship, having been divested of almost half the total of agricultural lands in the peninsula by the Japanese (Huh 95). Many Koreans moved to the outskirts of a big city in the peninsula, shantytowns, while others migrated to foreign countries, including Manchuria, Japan, and USSR, to live in diaspora. It is noteworthy that it was after the mid-1930s that the large-scale migration abroad in colonial Korea occurred ${ }^{4}$ (Park 33-37) and that it was also the time when the colonial mobility system was almost completed with the "12 Years Plan of Korean Railroad." Inevitably, the Koreans who had moved to the outskirts and those who had left behind their hometowns had to depend on colonial mobility in order to make a living. To view it from a different perspective, their survival depended upon imperialistic biopower.

It is noteworthy that, in 1931, the Japanese Government-General of Korea propelled the large-scale public works, centering on the construction of mobility infrastructures mentioned above. This was undertaken in the name of "poverty relief" that was designed to employ Koreans at the construction sites, transforming them into wage laborers, where they were paid meager salaries (J. Lee 123-129). Later, the Japanese colonial regime even publicized these mobility infrastructures as proof of the success of colonization. In the introduction to the section on traffic, transportation, and communication in "History of 25 years of Government" (1935), Japanese propaganda claimed that the colonial regime helped to rescue Koreans from their poverty by cultivating their ethos of diligence and savings (139). However, in practice, these construction projects did not help improve the lives of the Koreans. This is due to the fact that the wages that the Koreans earned were extremely low (J. Lee 137-140). That is, the Japanization of the Korean territory ${ }^{5}$ was undertaken by way of building new roads nationwide, while intensifying the Koreans' subjugation to the imperialistic biopower. 
It is essential not to forget that colonial mobility was forged principally for Japanese imperialistic administrative and military purposes. Most of all, through the improved mobility system in the late 1930s, the colonial government exercised its administrative power to mobilize the Korean population across the country, for a series of wars, including the Second Sino-Japanese War (1937) and the Pacific War (1941) in which they were considered merely as labor forces. For example, with the outbreak of the Second Sino-Japanese War, the Ministry of Interior and the Japanese Government-General of Korea conducted an administrative investigation on the workforce's whereabouts in every corner of the peninsula in the name of the deployment and regulation of the labor forces for the public works. The Ministry was particularly in search of "those who can labor," meaning those who are impoverished from 18 to 50 years (Kim 104-106). What this investigation suggests is that those worthy of being secured by the colonial biopower were simply those whose labor power the colonial regime could exploit, the labor forces. In this respect, the subjects the colonial government was particularly interested in were the mobile labor forces, who were likely to be forcibly transported to the battlefields or the other construction sites. These labor forces constituted colonial mobility, but without rights, in possession only of their mobile bare lives.

To summarize, the establishment of colonial mobility, alongside the imperialistic reorganization of the Korean territory, were accompanied by two interrelated phenomena: the production of beings on-the-move as the colonial subjects and the emergence of the non-place. Colonial mobility was an effective dispositif that could enable the colonial subjects to realize its purpose of stabilizing and perpetuating its colonial rule of Korea. For example, when they traveled somewhere, people had to acclimatize themselves to the altered mobile milieu by disciplining themselves according to the new traffic rules and regulations. They had to learn how to use trains, buses, and trucks, and move only through the new legal traffic networks (K. Lee 448-454). More importantly, they were beings who could either move to the construction sites or across the border for their survival or be forcibly mobilized to the battlefields. If they wanted to live in colonial Korea, they had to be beings who were worthy of being secured by the colonial biopower and suitable to colonial mobility who mattered only as labor forces; if they did not discipline themselves as such beings, they should leave or would be left behind in the colonized territory. In this respect, they are reduced to being bare lives on-the-move whose right to life and death, as well as their right to mobility, are owned by the colonial biopower.

As the colonized people became bare lives on-the-move, the Korean territories metamorphosed into non-anthropological spaces in which the mobile population developed a temporary and superficial relation with their environment. In such mobile spaces where the colonial government had relentlessly undertaken public works, it was not feasible for the colonized people to experience a fixed identity, 
intimate relations, and a long-term history. Traveling, moving, or being mobilized could only enable temporary and superficial relations with mobile spaces because the territories were being consistently (re)organized for imperialistic purposes, rather than for the people's sake. The mobile spaces, thus, become the non-places in which people live their bare lives as anonymous living beings. In other words, the non-places can be considered as colonial non-places, which are full of the bare lives on-the-move, that is, the biopolitically shaped beings divested of political rights.

Using Sharma's terminology, the colonial non-place can be considered as the mobile space in which the logic of spectacle and the camp work together; in the same vein, the non-anthropological relationship between the Korean population on-the-move and the Japanized Korean peninsula is contemporaneous with the colonial subjects as the living beings struggling to survive and who were divested of identity, relations, and history, as well as political rights. With the pervasiveness of the colonial non-places, the colonized people, residing in the non-places, had to live as living beings on-the-move, movable and mobilizable, by acknowledging such colonial non-places as their reality and adapting themselves to them, which thereby facilitated the stabilization and perpetuation of the colonial regime.

\section{“ON THE ROAD": A STORY ABOUT THE LATE COLONIAL KOREA}

Namcheon Kim's short story, "On the Road," depicts a narrator who is on his way back to Seoul from Chuncheon. Yeongchan Park, the narrator, encounters K, a civil engineer, and stays overnight at the temporary residence next to the construction site. Notable in this story first is a scene in its introduction where Park receives the white glass bottle containing three terrapins-which Park requested the night before-as mementos from $\mathrm{K}$. Throughout the narrative, Park gazes and ponders over them, reflecting on their affinity to laborers, who may be inferred to be Koreans in the context of the emergence of Korean, and Gilnyu-a girl working at the construction site whom he happens to encounter at the bus stop. Meanwhile, $\mathrm{K}$ regards them only from the viewpoint of the agency in charge of the railway construction, the Japanese imperialistic businesses. For the civil engineer, humans are merely deemed to constitute mobilizable labor forces for the construction sites.

What is notable in construing this work would be its background: the railway construction site. In this short story, the narrative begins with the encounter of Park and K, which occurs in the Korean countryside as the bus that Park rides has a flat tire. In this scene, the passengers who get off on the road watch the landscape, which is composed mainly of "a railway track which stretched out into as if it drew 
a parallel line to the Gyeongchun [Seoul-Chuncheon] highway," "the construction site build-up dirt," and "the new road" (Kim 230-231).

What this landscape suggests is that the reorganization of the Korean territories, centering on mobility infrastructures, had been developed considerably, transforming them into mobile spaces. Park finds "a young man," K, who comes over "from the middle of the construction site where twenty workers were walking around" (231). The description implies that in the mobile spaces around the construction site, a kind of temporary and superficial relation is formed between them. But even though Park eats and drinks with $\mathrm{K}$ and his subordinates and stays overnight at K's temporary residence, his overnight stay in a mobile space does not evoke in him any sense of affinity or attachment with them. Hence, as mentioned previously, there seems to exist only a transient and fairly meaningless relationship between them in the colonial non-places.

Also, it is essential to pay attention to Kim's short story's temporality of the late 1930s, which is manifestly registered in such details as the Gyeongchun Railroad Line [Seoul-Chuncheon] which was a part of the "12 Years Plan of Korean Railroad" (1927-1938), and the Jungang Railroad Line, which was a new mobility infrastructure construction plan (1936-1941). It was when the colonial traffic networks in the Korean territory were virtually completed. It was also during that time that the colonial government was aggressively laying the groundwork for the other catastrophic war, the Pacific War, that publicized the stabilization of the colonial regime towards the 3oth Anniversary Exhibition of Colonial Administration (1940). Therefore, the literary text's historical-political context would be indispensable in interpreting story, although it could not have been articulated explicitly due to fierce censorship by the Japanese Government-General of Korea. It is the interplay of the text and context that allows the reader to interpret Kim's work in terms of the possibility of postcolonial politics, precisely by situating the story in the historicalpolitical context of the late colonial era.

The following discussion explores the imperialistic biopower and its production of the colonial subjects who reside in the mobile non-place. In this space, they live the bare lives on-the-move divested of any identity, relations, and history, as well as political rights. On the other hand, it also suggests the impossibility of Japanese imperialism mainly by focusing on what occurs in the colonial non-places-on the road, bus stop, and the interior of the bus-which were established by the colonial mobility system. 


\section{ON THE ROAD: IMPERIALISTIC BIOPOWER AND BEINGS-LIKE-ZOĒ}

The colonial non-place to be analyzed first is situated on the road next to the railway construction site. The following morning after sojourning overnight at K's temporary residence, Park is informed by K regarding the laborers' lives working on the construction sites while traveling toward the bus stop to return to Seoul. Walking along the new road next to the almost-completed railway, K recounts the subject of "life," alluding to the terrapin's life as an example of life in general. Whereas his point here is ostensibly to criticize humanitarianism as an ideology, his real intention is to argue that "life" can be sacrificed for a large-scale business. K explains his point as follows:

To cite an example, there is a case in which a tunnel's ceiling collapses or an accident occurs due to the laborers' carelessness of gunpowder or explosives. In such a case, now, I certainly prefer the dead to the injured among the victims. In the case of the dead, it is enough to pay for funeral expenses, and their families might receive one or two hundred KRW, if at all. On the other hand, I hate the severely injured, who takes a month or two to recover, as well as by having to spend money. At this moment, I know that the humanitarian's righteous indignation would not be highly appreciated. Isn't it true that people's lives have always been sacrificed like bits of straw for large-scale business; but without such sacrifices, would the completion of such business be feasible? I know, people's lives are regarded lightly in this case but that does not mean that they really ought to be valued lightly. Look at these terrapins... (237; translation mine)

The above-quoted passage is the scene in which, looking around the railway construction site and the laborers working there, $\mathrm{K}$ talks with Park about the employees' lives. Kargues that their lives are fundamentally not different from those of the terrapins, as they can be sacrificed for large-scale business. He says, however, that it is not relevant to assume the sameness between laborers and terrapins, adding: "Nevertheless, it does not mean to put terrapins and human beings at the same place ..." (237). Given that his utterances put emphasis manifestly on the possible sacrifice of laborers for a large-scale business, his remark may be taken to be a lame excuse for his non-humanitarian standpoint. In this scene, K endeavors to justify his non-humanitarianism by assuming the equivalence of all lives: "when we weigh all the things, there is nothing different among them" (237).

From K's perspective, terrapins are not precious creatures to be respected, but things to be manipulated for his enjoyment; in fact, K plays with terrapins at home every evening, treating them as playthings. It is noteworthy that he plays with them just in the same way he disposes of his employees in the workplace. Thus, laborers and terrapins, both his objects of manipulation, are similarly divested of political right to decide whether to live or die. As the objects of manipulation, they can be 
mobilized anytime for K's purposes. In this respect, K's non-humanitarianism can be said to be due to his sole interest in mobilizing and managing laborers' lives and deaths effectively for the sake of the ongoing construction. Thus, mobilizing lives for a construction site becomes akin to mobilizing deaths to a funeral hall. They have no right to decide where they are mobilized, not even the manner in which they live or die.

In his well-known book Homo Sacer (1998), Giorgio Agamben denominated an individual or a group without any political rights as a $z o \bar{e}$, which simply refers to having existed like all other living beings. As such, it is different from bios who are in possession of political rights and responsibilities, which refers to a form or way of living appropriate to an individual or a group (Agamben 1). Thus, zoē is defined as bare life, namely, the life of homo sacer, who may be killed and yet not sacrificed (8). At this point, homo sacer's life and death are the same in their presumed triviality and worthlessness. Drawing on Agamben's arguments, K's terrapins and employees and homo sacer are similar. They are both the bare lives, beings with unworthy lives who are divested of authority even over their own life and death, that is, the beings-like-zoè. In other words, they are the beings-like-zoe who, irrespectively of their will, can be mobilized anywhere, whether a workplace or a funeral hall.

On the other hand, the employees laboring on the railway construction site are not merely trivial and worthless living beings. Instead, they are the labor forces that enable the colonial regime to build mobility infrastructures and reorganize the Korean territories. They are the builders of the colonial non-places, including "on the road," wherein Park and K encounter each other. Here, the materialization of imperialistic biopower is demonstrated. Indeed, the employees are the indispensable labor forces who are virtually able to do the job of conducting large-scale businesses for the Japanese imperialistic purposes. In short, their identity consists not only of being living beings divested of all the rights as bare lives-for they are also "those who can labor," residing in the colonial non-place and, ultimately, building colonial mobility and reinforcing the Japanese colonial regime.

It is noteworthy that, even if they own their labor power, the authority over their life and death would be wielded by the imperialistic biopower. It suggests that the population residing in the colonized territories, laborers represented as terrapins in the colonial non-place, is most of all characterized as $z o \bar{e}$ as the bare lives, as well as homo sacer. From the viewpoint of the imperialistic biopower, they are merely manipulatable and mobilizable tools for the large-scale imperialistic businesses. Their worthiness can be acknowledged only as labor forces, not as human beings. Paradoxically, they live bare lives in the sense that they can only matter for the colonial government as indispensable labor forces for the construction of colonial 
mobility but are deemed worthless as they are divested of political rights. In the colonial non-place, the colonial population, the employees, and terrapins are all beings-like-zoē.

\section{AT THE BUS STOP: HUMANITARIANISM, BIOLEGITIMACY, AND DOCILE BODIES}

As their conversation regarding "life" is almost concluded, Park and K arrive at the bus stop from where Park will take the bus to Seoul and K will see his company off. Notably, K behaves in this scene as if he is a humanitarian, which is ostensibly incongruous with his standpoint that gives more importance to large-scale business than to the protection of human life. At the bus stop, K finds a girl called Gilnyu and asks about her destination.

"As the construction, I worked for, is completed, we now move to the Jungang Railroad Line construction site," is the response. And then, a little girl called Gilnyu turned her eye toward her mother and little sister sitting in the back.

He asked again, "Where exactly are you going to in the Jungang Railroad Line?" She answered, "Even the person who came here to recruit workers said that he also had no idea, that you would know it when you were there."

"I hope the bus is not full." / "We are waiting for a truck here."

"Is your father going to come here by riding a truck?"

She said, "Yes," and then moved to her mother's side because her little sister was whining. K bought about $1.2 \mathrm{~kg}$ of cookies at the store and gave them to her.

"Eat with your sisters on the road." (Kim 238; translation mine)

In the above quotation, $\mathrm{K}$ behaves like a humanitarian, purchasing a lot of cookies at the store and offering them to Gilnyu. Considering that he professed the worthlessness of humanitarianism the previous night, his sudden altruism might seem absurd.

Discussing humanitarianism as the quintessential form of biopolitics, Didier Fassin argues that humanitarianism is "a moral principle that grants human life absolute priority" (Lemke 88) and coins the term "biolegitimacy," which refers to "the sacredness of life as such" (Fassin 50). He makes the point that humanitarianism is not about "human rights in general" but "the right to live in particular" (50). In other words, while recognizing "biolegitimacy" in general, humanitarianism is exercised by presuming the differences in the worth of life and the social segregation accorded to them, acknowledging the "space of humanitarian exception" as the space of worthy lives (52-57). Using Fassin's terminology, K's humanitarianism can be demonstrated in his segregation of Gilnyu's family from the severely injured, 
thus placing preference on the right to live in particular. In other words, contrary to the severely injured, Gilnyu's family are worthy lives who are mobilizable in the construction sites. Accordingly, K's humanitarianism is also worthy just for the latter, but worthless for the former. The railway construction sites can be deemed as the "space of humanitarian exception," where the worthy reside, the family of Gilnyu.

It is notable that humanitarianism is ultimately based on biolegitimacy as "the sacredness of life as such," which can refer only to the worthy lives. Since, for K, the worthy lives are the mobilizable beings for the imperialistic purposes-that is, the beings-like-zoè, who only seek their survival-biolegitimacy can be conjugated to discipline the colonial population in the way of acknowledging their life itself, despite being divested of their political rights. In other words, K's humanitarianism can be characterized as a moral principle that monetizes colonial subjects as the bare lives. As the bare lives are possibly on-the-move across the country or the border for their survival, fixed identity, intimate relations, and a long-term history in the colonial non-places is difficult to formulate. Instead, they are incessantly mobilized to take part in large-scale businesses. On the condition that they obey "the sacredness of life as such," they would survive as bare lives on-the-move, worthy beings to the colonial government, through colonial mobility.

Given that Gilnyu's family is part of the colonial government, the members may be referred to as "docile bodies," the term that Michel Foucault uses to refer to the manufacture of the modern subject through discipline. ${ }^{6}$ From this view, biolegitimacy does not pertain to people in general, but to certain groups of people in particular. These are the colonial subjects as the "docile bodies" who are willing to surrender their political rights in order to secure their lives. It is notable that in the story, without even confirming their destinations, the colonized take the bus to the Junganga Railroad Line construction site solely in order to make a living. They only vaguely knew that they would work somewhere in the construction site and nothing more; knowing not where they would arrive, sojourn, or work next. Their ignorance suggests their total dependency on colonial mobility, in which they do not have the right to choose where they travel to be able to work. It implies their willingness to be beings on-the-move for their survival; to be disciplined by the moral principle of humanitarianism based on biolegitimacy. They are the pliant bodies, the worthy beings as bare lives, who can thus, ironically, engage in stabilizing the colonial regime.

The colonial population and the imperialistic biopower might be said to work together harmoniously by making a codependent relationship that can be assured mainly in the transformation of the colonial population into "docile bodies." By this process, the colonial population can secure their lives, and the imperialistic 
biopower can conduct a series of large-scale businesses successfully; the latter can form the space of spectacle, while the former can present themselves as bare lives. For K, Gilnyu's family members are all bare lives who can move and seek only for life itself, irrespective of their destination. In short, by utilizing humanitarianism, the imperialistic biopower can produce the colonial subjects who discipline themselves according to biolegitimacy; in this, people are the beings on-the-move, securing their lives in the interest of imperialistic businesses.

\section{THE INTERIOR OF THE BUS: BARE LIVES ON-THE-MOVE AND POSTCOLONIAL POLITICS}

The interior of the bus to Seoul that Park is riding can be considered another colonial non-place. Here, Park tries but fails to carry to his home in Seoul the glass bottle containing three terrapins he received from $\mathrm{K}$. It is noteworthy that his failure problematizes the colonial non-place-where the colonial subjects reside-which is described from the viewpoint of "I," as follows:

Without holding on to my chair as I tried to rearrange my posture, the glass bottle containing terrapins which I held with one hand, hit the window bars, and was broken. While I was frantic, the broken bottle spilled water and sands onto my arm and knee. At this time, two of the three terrapins were thrown out of the window, and the rest fell down my shoes. Grabbing a piece of broken glass, I cried: "Stop driving!" But the driver did not hear me due to the bus engine's noise, and the passengers sitting next to me seemed to dislike me, as if to think, "Why terrapins, why is the old man carrying the terrapins! They are so common in the Han River." Then, I cried again, "Hey, driver, stop!" but the bus did not pay attention to what I said in the more embarrassed and low tone (Kim 239-240; translation mine)

In the scene just before the above quotation, Park endeavors with all his heart to take care of three terrapins in the glass bottle, remembering the scene in which $\mathrm{K}$ was playing with them. This is because Park sees in them an analogy of the colonial population, including the employees, Gilnyu's family members, and probably himself. Specifically, based on an ontological equivalence of all the living beings as the beings-like-zoè, the bare lives, in the colonial non-place, Park seems to react to K's humanitarianism with his trivial gesture of caring for them, implying that they should not be manipulated, mobilized, and ultimately sacrificed anymore. Thus, Park's caring for the terrapins may be acknowledged as an alternative biopolitics to K's imperialistic biopolitics, in which living beings are sacrificed for its purposes. Park's caring is one that assumes that living beings are to be cared for. Nonetheless, this biopolitics of caring does not seem any different in practice 
from the imperialistic biopolitics in their preference for life itself, in the sense of biolegitimacy. From this perspective, they both assume people only as biological beings, not as political beings, and, therefore, essentially not any different from the terrapins.

After losing his grip on the glass bottle containing three terrapins due to the bouncing of the bus, Park shouts at the driver, "Stop driving!" However, his cry is silenced on account of the bus engine's noise, which could be construed as emblematic of colonial mobility technologies. Given the ontological equivalence of all the living beings in the colonized territory, Park's silenced cry seems to connote the voice of the colonial subjects, rendered voiceless and divested of political rights in the colonial non-place, who cannot control his fate but can only follow its movement. Using Agamben's terminology, it can be viewed as a voice of the bare life that the colonial government refuses to hear, regarding it as a worthless noise, audible but incomprehensible and, thus, negligible, "the exclusive inclusion of bare life" (Agamben 70). Thus, Park's words-“Stop driving!"-could be taken as a cry for an end to colonial mobility, the exercise of the imperialistic biopower as its force, and the deprivation of humanity in the name of humanitarianism.

It might be worth looking more closely into the scene in which two of the three terrapins go out the window. At first, it might be viewed in terms of people stepping outside the confines of the colonial mobility system on which their lives wholly depend and through which their movements are managed and controlled. This incident can also be construed to denote an escape from the biopolitical frame of "the exclusive inclusion of bare life." At the same time, considering that such escape finally could result in their death, the event may be interpreted as an impossibility of the escape from the imperialistic biopower. From this perspective, Park's failure to care for the terrapins might imply not only the frustration of the biopolitics of caring but also the underlying insecurity of their lives. There seem to be only two interrelated alternatives for the colonial population: one is biological life, the singular inclusion of bare life, and the other is a biological death, the absolute exclusion of bare life. Given that the imperialistic humanitarianism is based on the permissible sacrifice of the colonial population for its large-scale businesses and a series of public works and wars, the bare lives' deaths would necessarily be the byproducts of the colonial regime.

Although the colonial regime operates by mobilizing the bare lives' labor, which is incessantly in danger in such non-places, it cannot assure its stabilization and perpetuation. By its nature, in the colonial non-place, the colonized people are expected to be always, already prepared to be mobilized somewhere; and as such, they are not able to experience any stable identity, relation, or history. They can have an opportunity to go out the window of the colonial regime only to find themselves 
in a funeral hall. Otherwise, when they desire to sojourn in the colonial non-places for their survival, they should acknowledge their existence as bare lives on-themove, mobilizable by the colonial government to any place. On account of their lack of identity, relations, and history-their biological state of being-fostered politically by the imperialistic biopower, the Japanese colonial regime ultimately could not aspire for its stabilization and perpetuation. In other words, the colonial regime could not persist because it was laden with insecurities and dangers in its space-thus, imposing upon the colonial subjects Japanese identity, relations, and history was not possible. Without subjects with rights, no regime could be established.

The colonial non-place might be characterized as a porous space. Significantly, this space is constituted not only by imperialistic biopower but also by the possibility of postcolonial politics. When Park endeavors to take care of the terrapins, when the terrapins go beyond the border of colonial mobility, and when Park cries"Stop driving!" - possibilities begin to open for the colonialized territory, thereby disclosing its porousness, no matter how puny and forcibly suppressed. In other words, due to the colonial population's ontological condition-that is, as the being like-zoe and bare lives on-the-move-and the colonial territory's structural porousness - that is, the deprivation of stable identity, relations, and history-the alleged security and solidity of the colonial regime is constantly undermined. The prevalence of the colonial non-place in the colonial territory, therefore, exposes the vulnerability of Japanese imperialism and reveals, at the same time, the possibility of postcolonial politics. The postcolonial politics is at the core of colonial mobility.

\section{CONCLUSION}

In his short story, "On the Road," Namcheon Kim portrays the Korean territories in the late colonial era as the non-places-specifically on the road, at the bus stop, and the interior of the bus-wherein the imperialistic biopower endeavors to perpetuate itself by building colonial mobility and by managing the population through it. By a kind of allegorical reading operation drawn from the analogical association of the terrapins with the bare lives, the short story articulates the ontological conditions of the colonial population in the colonial non-place, which can be manipulated, mobilized, and sacrificed. From the viewpoint of K, an actor of the colonial government, the colonized people are considered as the beingslike-zoè, the bare lives on-the-move, who are divested of political rights but can be made to survive by being mobilized and made to participate in the imperialistic business as labor forces. They are "docile bodies" who can discipline themselves by responding to imperialistic humanitarianism. At the same time, it also discloses 
the possibility of postcolonial politics, which lurks at the core of colonial mobility, by depicting the scene of Park's failure to bring the terrapins to Seoul, consisting of Park's caring for the terrapins, their escape from the bus, and his desperate cry to the bus driver.

The colonial non-place is the space where resides the biological population, which has been shaped politically by the colonial government and is laden with biopolitical implications. It is also the porous space in which imperialistic biopower is exercised through the bare lives as "docile bodies" but where no Japanese subjects reside because the colonial population is considered the bare life and on-the-move. In this space, the voices of the docile bodies are inaudible, silenced, and nullified on account of the noise brought about by colonial mobility technologies. However, contained within it are loopholes through which postcolonial biopolitics lurks, waiting to happen and question the stability of the Japanese colonial regime. What Kim's work demonstrates, thus, would be the ontological impossibility of Japanese imperialism that endeavors to reorganize the colonial territory and expand its empire via colonial mobility.

In the context of 1939 when this short story was written, its implications can be articulated more clearly: It was the time when the Japanese Government-General of Korea was preparing for the most prominent ceremony in the history of colonial Korea in celebration of the Japanese colonialism's fruition-the 3oth Anniversary Exhibition of Colonial Administration (1940). At the same time the Japanese were aggressively making preparations for the Pacific War (1941), assuming that it had attained the stabilization and perpetuation of the colonial regime. As mentioned previously, such stabilization and perpetuation of the colonial regime could only mean fundamentally the deformation of the colonial population into homo sacer and the non-anthropologicalization of their territories. Drawing on this, the analysis of "On the Road," a story in which are inscribed the colonial non-place and the bare lives, would reveal an impasse of Japanese imperialism and its impossible sustainability - a reality that had been concealed by the colonial power in the last 30 years. 


\section{Notes}

All quotations in this article are my translations.

1. Considering the temporal and spatial flexibility of the non-place, Peter Merriman criticized Augé's chronology of supermodernity stating that he overstated its newness and differences and that the experience of the non-place came with the emergence of such diverse (new) technologies as the stagecoach, railway, telegraph, telephone, and the motor car in modernity (Merriman 150).

2. For Sharma, "a mixed regime of camp and spectacle" can be exemplified by the New Orleans Superdome, a spectacular sporting complex, the various convention centers which functioned as "refugee" areas during the aftermath of Hurricane Katrina, as well as the rise of lifestyle lounges at international airports in the UK and the US, which are directly related to the increased security measures post-9/11 (Sharma 144-145). In this paper, as Sharma asserts, the logic of camp denotes the space in which resides the living creatures divested of any rights, "bare lives." On the other hand, to distinguish her reference to the space of consumption, the logic of spectacle here pertains to the space of transition in which temporary and superficial relations, "the bare lifestyle," are pervasive.

3. The Japanese Resident-General of Korea was the government organization that Japanese imperialism set up in the Korean Peninsula in the name of stability and peace of the Korean imperial family in February 1906. It had exercised its substantive power of government by August 1910, when the Japanese Government-General of Korea, as the Japanese colonial government organization, was inaugurated.

4. The large-scale migration of the Korean population also had been enacted as part of the Japanese policy of the development of Manchuria in the mid-1930s, which strongly induced the Koreans to move to Manchuria around 1940, the start of the Pacific War (Park 44-51).

5. The Japanization of the Korean territory is also demonstrated manifestly in the fact that the Japanese financial capitalists owned almost 62 percent of the total Korean land in 1929 (Lee and Cheon 210).

6. According to Foucault, "docile bodies" refers to living bodies who conjoin the analyzable body to the manipulatable body, an intelligible body to a useful body (Foucault 136). In Kim's short story, the colonized population can be characterized as "docile bodies" because they are deemed as labor forces that are numerable, not human beings that are uncountable, and, as the bare lives on-the-move, they are mobilizable for imperialistic businesses. 


\section{Works Cited}

Agamben, Giorgio. Homo Sacer: Sovereign Power and Bare Life. Translated by Daniel Heller-Roazen, Stanford UP, 1998.

Augé, Marc. Non-Places: Introduction to an Anthropology of Supermodernity. Translated by John Howe, Verso, 1995.

Cho, Byunglo. "A Study on Road Traffic in the Japanese Colonial Period (I)." Journal of Studies on Korean National Movement, no. 59, 2009, pp. 5-37.

Cho, Byunglo, et al. "A Study on Road Traffic in the Japanese Colonial Period (II)." Journal of Studies on Korean National Movement, no. 61, 2009, pp. 257-290.

Cresswell, Tim. Place: A Short Introduction. Blackwell Pub., 2004.

Fassin, Didier. "Another Politics of Life is Possible." Theory, Culture E Society, vol. 26, no. 5, 2009, pp. 44-60.

Foucault, Michel. Discipline and Punish. Translated by Alan Sheridan, Vintage, 1979.

Huh, Sooyeol. Development without Development. Eunhaengnamu Pub., 2005.

Huh, Wookung and Hiroshi Todoroki. A Geography of Inland Transport in the Gyonsangdo Region of Korea, from the Late Nineteenth to the Early Twentieth Centuries. SNU P, 2007.

Jeong, Jaejung. Japanese Invasion and Korean Railroad (1892 1945). SNU P, 1999.

Kim, Insoo. "The Representation-Politics of Colonial Korea During the Total War Period: Focus on the Discourse on Flows of Korean Labour Force and Rice." Sogang Humanities Journal, no. 47, 2016, pp. 85-127.

Kim, Namcheon. "On the Road." Munjang, vol. 1, no. 7 (an extra number), 1939, pp. 230-240.

Ko, Taewoo. "Civil Administration and 'the Development of Joseon' by the Japanese Government-General of Korea." History \& the Boundaries, no. 97, 2015, pp. 271-320.

Lee, Geyhyeong, and Hyunmoo Cheon. Colonial Korea Seen from the Viewpoint of Number. Yeoksagonggan, 2014.

Lee, Jongbum. "The Characteristics of the 'Public Works for Poor Relief' in the Early 1930s." Chonnam Historical Review, no. 2, 1988, pp. 121-154.

Lee, Kihoon. "Another Face of the Modern Train." Culture E Science, no. 86, 2016, pp. $436-454$.

Lee, Yongsang, and Byunghyun Chung. "A Qualitative Study of the Properties of the Korean Railway during the Japan Colonial Period." Journal of the Korean Society for Railway, vol. 15, no. 3, 2012, pp. 306-314.

Lemke, Thomas. Biopolitics: An Advanced Introduction. New York UP, 2011.

Merriman, Peter. "Driving Places: Marc Augé, Non-Places, and the Geographies of England's M1 Motorway.” Theory, Culture \& Society, vol. 21 no. 4/5, 2004, pp. 145-167.

Park, Keongsook. "Population Dynamics of Korea during the Colonization Period (19101945)." Korea Journal of Population Studies, vol. 32, no. 2, 2009, pp. 29-58.

Sharma, Sarah. "Baring Life and Lifestyle in the Non-Place." Cultural Studies, vol. 23, no. 1, 2009, pp. 129-148. 
Sheller, Mimi. "From Spatial Turn to Mobilities Turn." Current Sociology, vol. 65, no. 4, 2017, pp. 1-17.

The Japanese Government-General of Korea. "History of 25 years of Government." $A$ History of 30 years of the Japanese Government-General of Korea. Translated by Chanseung Park, Minseok Kim, Eunjin Choi, and Jihye Yang, Minsokwon, 2018.

Urry, John. Mobilities. Polity, 2007. 